\title{
Distinct neurometabolic profiles are evident in the anterior cingulate of young people with major psychiatric disorders
}

\author{
DF Hermens ${ }^{*}$ J Lagopoulos, SL Naismith, J Tobias-Webb and IB Hickie
}

Currently, there are no validated neurobiological methods for distinguishing different pathophysiological pathways in young patients presenting in the early phases of major psychiatric disorders. Hence, treatments are delivered simply on the basis of their possible effects on nonspecific symptom constructs such as depression, cognitive change or psychotic symptoms. In this study, the ratios (relative to creatine) of key metabolites ( $\mathrm{N}$-acetyl aspartate, myoinositol, glutamate and glutathione) were measured with proton magnetic resonance spectroscopy ( $\left.{ }^{1} \mathrm{H}-\mathrm{MRS}\right)$ within the anterior cingulate cortex of 88 young persons presenting with major mood or psychotic symptoms. We derived empirically (using a cluster analytical technique) three subgroups of subjects on the basis of their patterns of in vivo brain biochemistry. The three subgroups were distinguished (from each other) by all the four metabolites, in particular, glutathione and glutamate. By contrast, the groups could not be distinguished by differences in terms of other demographic, functional or clinical measures. We propose that this ${ }^{1} \mathrm{H}$-MRS-based subclassification system could be used as the basis for much more specific tests of novel intervention strategies (notably, antioxidant and glutamatergic therapies) early in the course of major psychiatric disorders.

Translational Psychiatry (2012) 2, e110; doi:10.1038/tp.2012.35; published online 8 May 2012

\section{Introduction}

The failure to identify clear neurobiological markers of the pathophysiological pathways underpinning the severe mood or psychotic disorders remains a major limitation in clinical psychiatry. Currently-used diagnostic categories map poorly onto proposed risk factors or persistent pathophysiology. An alternative clinical strategy has been to focus attention more specifically on those in the earliest active phases of the major mood and psychotic disorders. ${ }^{1}$ However, young persons (typically 15-25 years) presenting to care close to the onset of illness typically report admixtures of anxiety, depressive, hypomanic or psychotic symptoms. ${ }^{2}$ Although clearly disabled by these symptoms, ${ }^{3}$ they do not fit readily into current diagnostic categories.

The development of a clinical staging model to categorize these various early phases of illness is useful for testing the benefits of a variety of intervention strategies. ${ }^{1,4,5}$ However, the real utility of these promising 'pre-emptive' 6 or 'early intervention, ${ }^{7}$ strategies may well depend on our capacity to identify genuine neurobiological markers of active pathophysiology during these early active phases of illness. Rather than assuming that current diagnostic systems relate to specific developmental or current pathophysiologies, we propose that group membership based on direct measures of brain structure or function may prove to be a more valid approach. ${ }^{8}$

In this study, we explore the capacity of four key markers to create novel groupings based on various biochemical measures derived by magnetic resonance spectroscopy (MRS). The four markers are: (i) $\mathrm{N}$-acetyl aspartate (NAA), a validated marker of neuronal density and viability ${ }^{9,10}$ (NAA is an amino acid thought to be present entirely within neurons and axons but absent in glial cells.) (ii) myoinositol (MI), which is purported to be only present in glial cells (specifically the astrocytes) and as such increased concentrations are thought to reflect glial activation; ${ }^{11}$ (iii) glutamate (GLU), which is the most abundant excitatory neurotransmitter (precise information processing is dependent on fast and efficient removal of glutamate from the synaptic cleft.) $;{ }^{12}$ and (iv) glutathione (GSH), which is a predominant intracellular antioxidant, principally involved in neutralizing reactive oxygen species generated within the brain.

Proton magnetic resonance spectroscopy ( ${ }^{1} \mathrm{H}$-MRS) has already produced a number of important insights into the neurobiology of a range of psychiatric conditions. Many of these studies have focused on (or included) the anterior cingulate cortex (ACC), a structure that has been implicated in the pathophysiology of several psychiatric disorders, including bipolar disorder, ${ }^{13}$ depression ${ }^{14,15}$ and schizophrenia. ${ }^{16,17}$ The ACC is critically involved in performance monitoring and cognitive control and has a key role in emotional and social behavior. ${ }^{18}$ The ACC comprises a dorsal (cognitive) division and a rostral-ventral (affective) division. The dorsal subdivision has been associated with modulation of attention to influence sensory or response selection, complex motor control and motivation. The rostral-ventral subdivision is

Clinical Research Unit, Brain and Mind Research Institute, University of Sydney, Camperdown, New South Wales, Australia

${ }^{*}$ Correspondence: Dr DF Hermens, Clinical Research Unit, Brain and Mind Research Institute, University of Sydney, 100 Mallet Street, Camperdown, NSW 2050, Australia. E-mail: daniel.hermens@sydney.edu.au

Keywords: anterior cingulate; glutamate; glutathione; psychiatric; spectroscopy; youth

Received 27 September 2011; revised 15 March 2012; accepted 5 April 2012 
thought to be primarily involved in assessing the salience of emotional and motivational information and the regulation of emotional responses.

Although there have been a significant number of studies of these markers, individually across a range of psychiatric disorders, few studies have assessed NAA, MI and GLU in the same individuals and none of the studies have included all four spectroscopic markers (including GSH). Although there are methodological differences, there appears to be little consistency within each diagnostic category, suggesting that other factors may be better matched with underlying brain changes.

Empirically-based approaches to subject grouping are not often employed in clinical psychiatry. In our view, such datadriven approaches may identify putative biomarkers that, with further experimental characterization, may describe or explain illness trajectories beyond (or in spite of) diagnostic phenotype. Such neurobiological markers may also be more predictive of disability, functional status, cognitive impairment or response to specific treatments. Cluster analysis is a classification technique for forming homogeneous groups within complex data sets. ${ }^{19}$ Ideally, a good cluster solution is obtained when the data segregate into theoretically meaningful subsets; ${ }^{20}$ in this sense, cluster analysis can be used as a hypothesis-generating technique. ${ }^{21}$ In this study, we performed a cluster analysis utilizing four key neurometabolites (ie NAA, MI, GLU and GSH) measured within the ACC in a large sample of young (16-30 years old), health-seeking psychiatric outpatients.

\section{Materials and methods}

Eighty eight outpatients aged 16-30 years were recruited from specialized referral services for the assessment and early intervention of mental health problems in young people. ${ }^{22}$ Patients were assessed by a psychiatrist, according to DSM-IV criteria, who also made a primary diagnosis of an axis I psychiatric disorder (ie depressive disorder $(n=37)$, bipolar disorder $(n=29)$ or psychotic disorder $(n=22)) .{ }^{23}$ All patients were receiving clinician-based case management and relevant psychosocial interventions at the time of assessment. Additionally, patients who were treated with psychotropic medications were assessed under 'treatment as usual' conditions, whereby their normal medications were not altered. At the time of assessment, $12 \%$ of the patients were not taking any psychotropic medications; $53 \%$ were taking a second-generation anti-depressant; $53 \%$ were taking an atypical antipsychotic medication; and $23 \%$ were taking a mood stabilizer. Of those medicated, 54\% were taking more than one of these psychotropic medications; for the majority of these patients ( $44 \%$ of those medicated) this polytherapy included an antidepressant.

The healthy control group $(n=25)$ was recruited from the community via advertisements. Exclusion criteria for all participants were medical instability (as determined by the treating psychiatrist), history of neurological disease (eg tumour, head trauma, epilepsy), medical illness known to impact cognitive and brain function (eg cancer, ECT in last 3 months), intellectual and/or developmental disability (a predicted IQ score $<70$ ), insufficient English for testing or psychiatric assessment and current substance dependence.
Participants were asked to abstain from drug and alcohol use for $48 \mathrm{~h}$ before testing. The study was approved by the University of Sydney Human Research Ethics Committee and all participants gave written informed consent.

Clinical assessment. An independent psychiatrist or trained research psychologist conducted a structured clinical interview to determine the nature and history of any mental health problems. This interview served as a means to screen control subjects for past psychiatric disorders and current symptoms. The interview included the Hamilton Depression Rating Scale (17-item) $)^{24}$ to quantify current mood symptoms; the Brief Psychiatric Rating Scale ${ }^{25}$ to quantify general psychiatric symptoms at the time of assessment; and the Social and Occupational Functioning Assessment Scale, ${ }^{26}$ where a participant's functioning is rated from 0 to 100 , with lower scores suggesting more severe impairment. All participants were also asked to complete the Kessler-10, ${ }^{27}$ which is a brief self-report instrument designed to detect psychological distress and affective caseness. ${ }^{28}$ As a proxy measure for duration of illness, the age at which each patient first engaged a mental health service was recorded.

${ }^{1} \mathrm{H}$-MRS data acquisition. ${ }^{1} \mathrm{H}-\mathrm{MRS}$ data were acquired using a 3-T GE Discovery MR750 MRI scanner (GE Medical Systems, Milwaukee, WI, USA), using an 8-channel-phased array head coil. The protocol comprised of a three-dimensional sagittal whole-brain scout for orientation and positioning of all subsequent scans (TR $=50 \mathrm{~ms}$; $T E=4 \mathrm{~ms}$; 256matrix; no averaging, $z=5 \mathrm{~mm}$ thickness). To aid in the anatomical localization of sampled voxels, a T1-weighted Magnetization Prepared RApid Gradient-Echo (MPRAGE) sequence producing 196 sagittal slices $(T R=7.2 \mathrm{~m}$; $\mathrm{TE}=2.8 \mathrm{~m}$; flip angle $=10^{\circ}$; matrix $256 \times 256 ; 0.9 \mathrm{~mm}$ isotropic voxels) was also acquired. Finally, single voxel ${ }^{1} \mathrm{H}$-MRS using a Point RESolved Spectroscopy (PRESS) acquisition with two chemical shift-selective imaging pulses for water suppression was acquired from a voxel placed midline in the ACC, with the following parameters: $T E=35 \mathrm{~m}$, $\mathrm{TR}=2000 \mathrm{~m}, 128$ averages voxel size $2 \times 2 \times 2 \mathrm{~cm}$. Anatomical localization of voxel placement was based on the Talaraich brain atlas ${ }^{29}$ and positioning was guided by the T1 MPRAGE image as shown in Figure 1. All spectra were shimmed (using automatic and manual higher-order shimming) to achieve full-width half maximum of $<13 \mathrm{~Hz}$. Before any postprocessing, all spectra were visually inspected, separately by two independent raters, to ensure the consistency of the data. Poorly fitted metabolite peaks as reflected by large Cramer-Rao Lower Bounds (CRLB) were excluded from further analysis. Subjects' data was included in this study if the CRLB was less than $20 \%$.

${ }^{1} \mathbf{H}$-MRS spectrum analysis. Spectra were quantified with the LCModel software package ${ }^{30}$ using a PRESS TE $=35$ basis set of 15 metabolites (included NAA, GLU, MI and GSH) and incorporating macromolecule and baseline fitting routines. The coordinates of the ACC voxels were determined in the SAGE (Spectroscopy Analysis GE) software package and the reconstructed acquisition voxels were then 


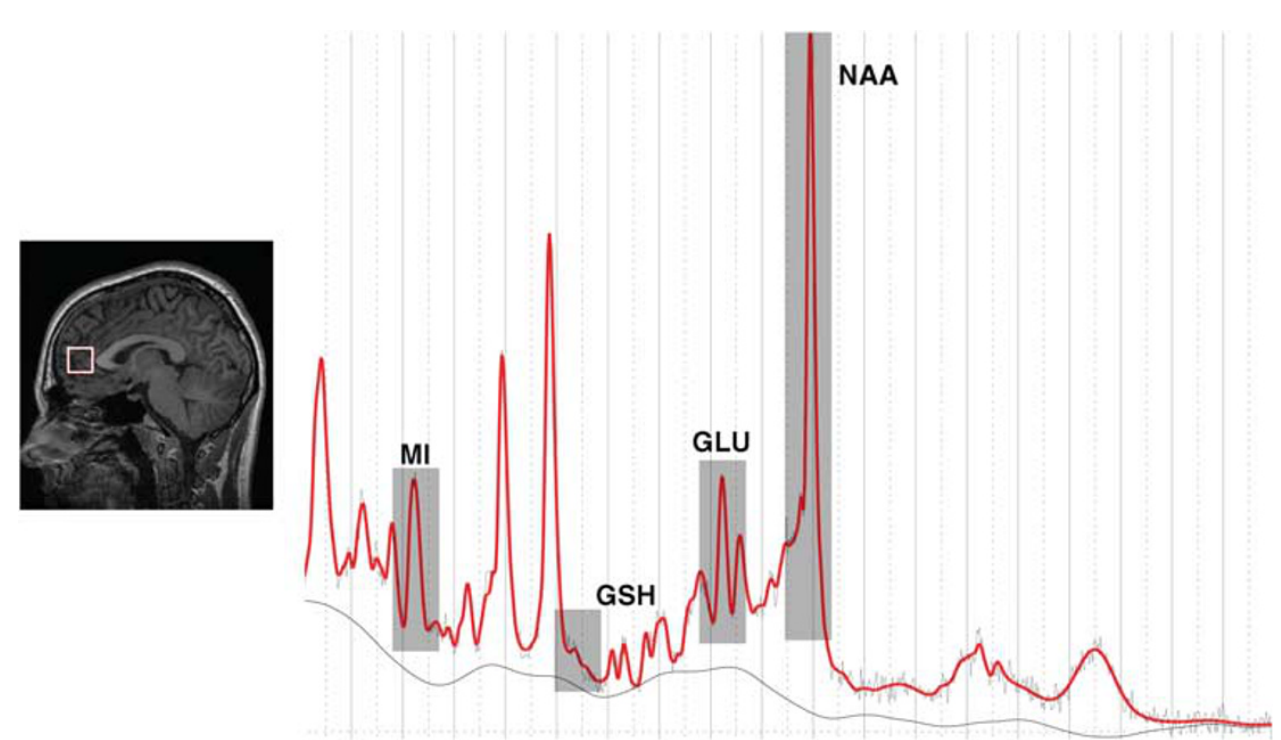

Figure 1 Left panel: Sagittal views of representative T1-weighted images illustrating the voxel placement for the anterior cingulate (white box). Right panel: Watersuppressed spectra (sampled from the anterior cingulate) processed using LCModel from a single representative subject. : GLU, glutamate; GSH, glutathione; MI, myoinositol; NAA, $N$-acetylaspartate.

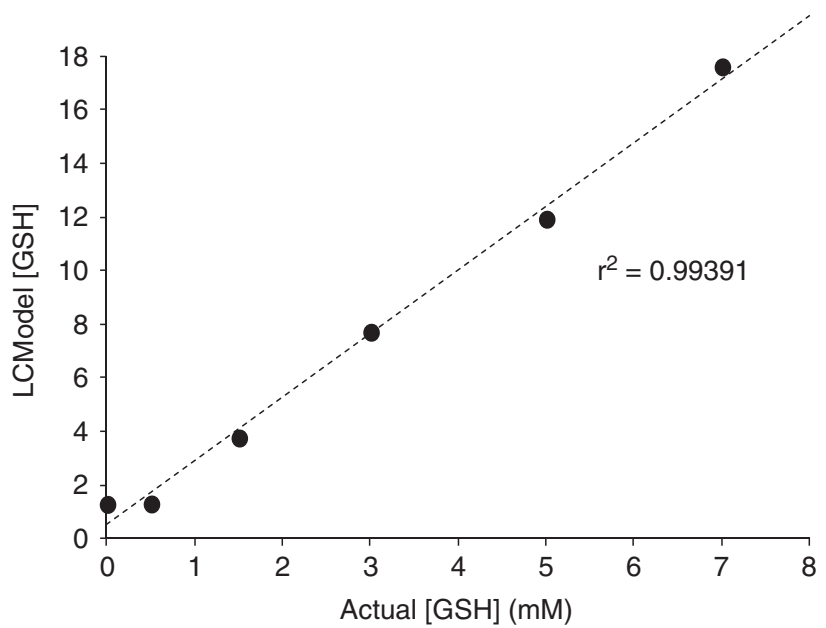

Figure 2 Results from an in vitro phantom study used to validate the GSH spectroscopy findings.

corrected for gray-matter content. For segmentation, individual structural images used for voxel placement were segmented into gray matter, white matter and CSF using the FAST4 algorithm as implemented in FSL. ${ }^{31}$ To determine the sensitivity of the acquisition technique and validate the GSH findings reported in this manuscript, we also undertook an in vitro phantom experiment. Varying physiological concentrations of $\mathrm{GSH}(0-7.0 \mathrm{mM})$ were mixed together with creatine, glutamate, glutamine and phosphate (which were all present in physiological brain concentrations), and the linear dependence of GSH was calculated to be $R^{2}=0.994$ (see Figure 2). Statistical analyses were then conducted on the following gray matter-corrected metabolites, NAA, MI, GLU and GSH. All subsequent metabolite levels were reported as ratios over creatine.
Statistical analyses. Statistical analyses were performed using SPSS for Windows 20.0. Values of the four MRS variables (NAA/Cr, MI/Cr, GLU/Cr, GSH/Cr), which were standardized across the sample of patients, so that they could be compared with each other. A hierarchical cluster analyses utilizing Wards method of minimum variance with a squared Euclidean distance measure was conducted to identify spectroscopic profiles. The cluster analysis technique was based on our previous neuropsychological study $^{8}$ and statistical recommendations. ${ }^{32}$

One-way between-subject analyses of variance (ANOVA) were used to assess the differences in demographic, functional and clinical variables among cluster groups. The $\chi^{2}$ test was used to compare the ratio of females to males across cluster groups. Significance levels were set at $P<0.05$. Effect sizes were calculated ( $d=$ mean difference/ mean s.d.) to evaluate pair-wise group comparisons (where $d>0.8$ was considered to be of large effect size). A confirmatory (standard) discriminant function analysis (DFA) was performed to determine which spectroscopic variables best distinguished the cluster groups.

\section{Results}

Cluster characteristics. Agglomeration coefficients generated by cluster analysis revealed a demarcation point between three- and four-cluster solutions, suggesting that a three-cluster solution best distinguished all the cases, which was subsequently confirmed by inspection of the dendrogram. The resultant clustering revealed three relatively well-sized groups (cluster 1: $n=20$; cluster 2: $n=28$; cluster 3: $n=29$ ), indicating that the appropriate number of clusters was selected. It should be noted that 11 cases were not included in the final analysis; 9 cases were excluded owing to CRLB scores, exceeding $20 \%$ for at least one spectroscopic variable, and 


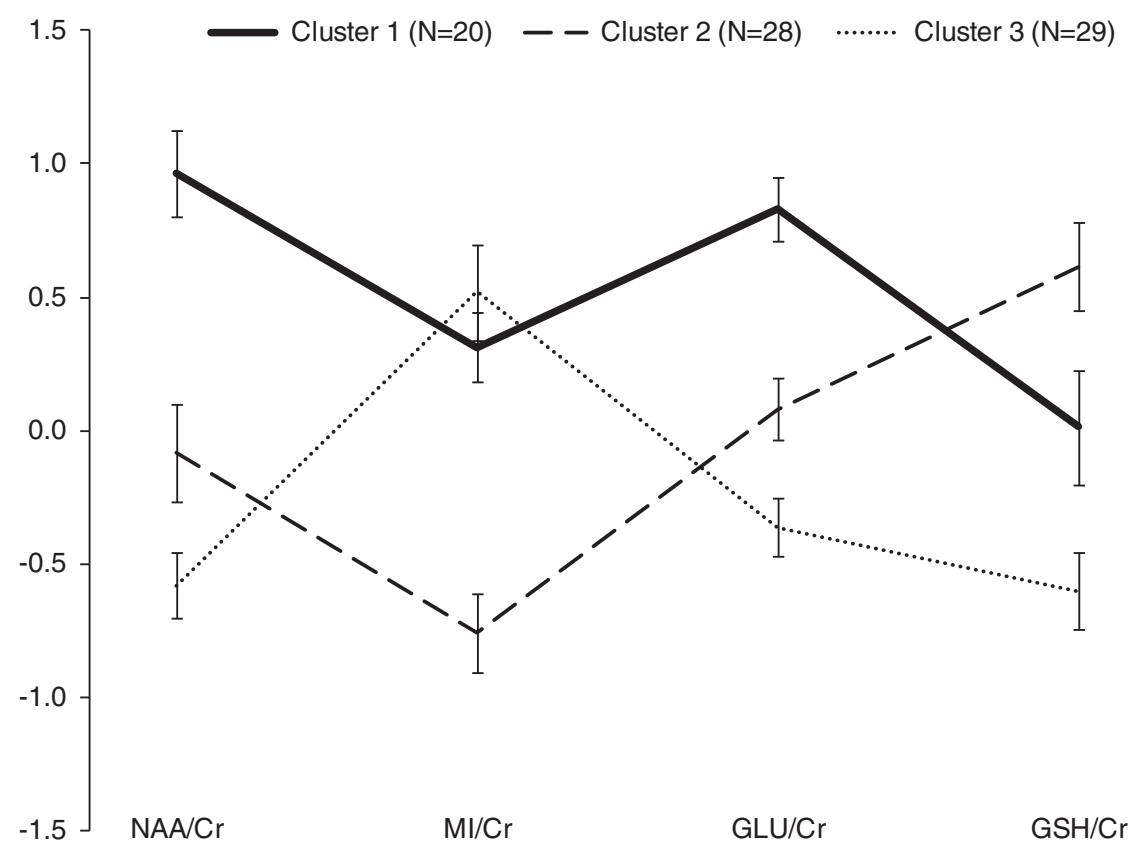

Figure 3 Profile of standardized scores (with s.e. bars) for ACC-derived spectroscopic (neurometabolite) variables by cluster group. Cr, creatine; GLU, glutamate; GSH, glutathione; Ml, myoinositol; NAA, N-acetylaspartate.

Table 1 Mean scores ( \pm s.d.) for demographic and clinical variables across clusters; between group differences were tested by $\chi^{2}$ or ANOVA

\begin{tabular}{|c|c|c|c|c|c|c|c|c|}
\hline & \multirow{2}{*}{$\begin{array}{c}\text { Cluster } 1 \\
(\mathrm{~N}=20)\end{array}$} & \multirow{2}{*}{$\begin{array}{c}\text { Cluster } 2 \\
(\mathrm{~N}=28)\end{array}$} & \multirow{2}{*}{$\begin{array}{c}\text { Cluster } 3 \\
(\mathrm{~N}=29)\end{array}$} & \multirow{2}{*}{$\begin{array}{c}\text { Significance } \\
\text { test }(\mathrm{P})\end{array}$} & \multicolumn{3}{|c|}{ Effect sizes, d } & \multirow{2}{*}{$\begin{array}{c}\text { Controls } \\
(\mathrm{N}=25)\end{array}$} \\
\hline & & & & & 1 vs 2 & 1 vs 3 & 2 vs 3 & \\
\hline $\operatorname{Sex}(f / m)$ & $11 / 9$ & $16 / 12$ & $15 / 14$ & $\chi^{2}(2,77)=0.2(0.918)$ & n.a. & n.a. & n.a. & $11 / 14$ \\
\hline Age, years & $22.0 \pm 3.6$ & $22.2 \pm 3.7$ & $22.8 \pm 4.0$ & $\widehat{F}(2,76)=0.3(0.745)$ & 0.1 & 0.2 & 0.1 & $23.0 \pm 2.6$ \\
\hline Predicted IQ & $104.5 \pm 6.8$ & $106.3 \pm 7.6$ & $103.8 \pm 7.7$ & $F(2,73)=0.8(0.454)$ & 0.2 & 0.1 & 0.3 & $104.8 \pm 8.2$ \\
\hline Education, years & $12.9 \pm 2.0$ & $13.8 \pm 2.4$ & $13.8 \pm 2.2$ & $F(2,76)=1.3(0.280)$ & 0.4 & 0.4 & 0.0 & $14.6 \pm 1.8$ \\
\hline SOFAS & $61.7 \pm 10.7$ & $62.9 \pm 11.8$ & $62.9 \pm 14.0$ & $F(2,73)=0.1(0.936)$ & 0.1 & 0.1 & 0.0 & $91.0 \pm 2.5$ \\
\hline $\mathrm{K}-10$ total & $29.7 \pm 8.7$ & $23.9 \pm 8.0$ & $25.2 \pm 8.4$ & $F(2,73)=2.7(.070)$ & 0.7 & 0.5 & 0.2 & $15.4 \pm 6.8$ \\
\hline HDRS total & $15.3 \pm 8.1$ & $11.1 \pm 6.7$ & $10.9 \pm 7.5$ & $F(2,75)=2.4(0.101)$ & 0.6 & 0.5 & 0.0 & $1.7 \pm 2.2$ \\
\hline BPRS total & $42.1 \pm 8.5$ & $39.9 \pm 8.9$ & $39.5 \pm 9.2$ & $F(2,74)=0.5(0.588)$ & 0.2 & 0.3 & 0.0 & $26.8 \pm 3.3$ \\
\hline
\end{tabular}

Abbreviations: ANOVA, analysis of variance; BPRS, Brief Psychiatric Rating Scale; f, female; HDRS, Hamilton Depression Rating Scale; K-10, Kessler-10; m, male; SOFAS, Social and Occupational Functioning Assessment Scale.

Effect sizes $(d)$ for each pair-wise cluster comparison are also provided. ${ }^{\dagger}$ denote large effect sizes $(d>0.8)$. Scores for the control group are also provided.

the remaining 2 because gray matter segmentation could not be performed owing to excessive movement or poor graywhite matter differentiation in the structural image. The resultant spectroscopic profiles for the three cluster groups are depicted in Figure 3. ANOVA determined significant (all $P<0.01$ ) main effects of cluster group for three of the four spectroscopic variables. As indicated in Figure 3, the largest effect sizes were evident for NAA/Cr (between clusters 1 and 3 ; $d=2.2$ ) and GLU/Cr (between clusters 1 and 3; $d=2.1$ ). Across all the four variables, the smallest difference observed was for Ml/Cr levels between cluster 1 and cluster $3(d=0.3)$.

The three cluster groups were compared in terms of demographic, functional and clinical variables (see Table 1). According to $\chi^{2}$ analysis, the clusters do not differ significantly in the distribution of each gender. ANOVAs for the subsequent variables revealed no main effects of cluster group for any of the remaining demographic, functional or clinical variables. Similarly, the three cluster groups did not differ significantly (according to $\chi^{2}$ tests) with respect to the distribution of primary diagnoses or type of medication (see Table 2).

Discriminant function analysis. With the four spectroscopic variables entered (simultaneously) as predictors, DFA confirmed the distinct neurometabolite profiles by generating two functions to separate the 3 cluster groups. The first function accounted for $60 \%$ of the differences among the clusters (Wilk's $\lambda=0.191, P<0.001$ ). The second function explained the remaining variance $(40 \%)$ and was also statistically significant (Wilk's $\lambda=0.490, P<0.001$ ). The structure matrix showed a clear delineation, with function-1 being characterized by a high discriminant loading for GLU/Cr $(r=0.716)$ and $\mathrm{MI} / \mathrm{Cr}(r=-0.803)$, whereas function-2 was characterized by $\mathrm{GSH} / \mathrm{Cr}(r=-0.753)$.

Comparison with healthy controls. As a secondary analysis, we sought to determine whether there were any potential abnormalities in the spectroscopic variables of each 
Table 2 Cross-tabulation of cluster-group by (a) primary diagnosis (top panel) and (b) type of current medication (bottom panel)

\begin{tabular}{|c|c|c|c|}
\hline & $\begin{array}{l}\text { Cluster } 1 \\
(\mathrm{~N}=20)\end{array}$ & $\begin{array}{c}\text { Cluster } 2 \\
(\mathbf{N}=28)\end{array}$ & $\begin{array}{l}\text { Cluster } \\
(\mathrm{N}=29)\end{array}$ \\
\hline \multicolumn{4}{|c|}{$\begin{array}{l}\text { (a) Primary diagnosis } \\
\text { Depression }\end{array}$} \\
\hline $\begin{array}{l}\text { Count } \\
\%\end{array}$ & $\begin{array}{c}10 \\
50.0 \%\end{array}$ & $\begin{array}{c}10 \\
35.7 \%\end{array}$ & $\begin{array}{c}15 \\
51.7 \%\end{array}$ \\
\hline \multicolumn{4}{|l|}{ Bipolar } \\
\hline $\begin{array}{l}\text { Count } \\
\%\end{array}$ & $\begin{array}{c}5 \\
25.0 \%\end{array}$ & $\begin{array}{c}7 \\
25.0 \%\end{array}$ & $\begin{array}{c}9 \\
31.0 \%\end{array}$ \\
\hline \multicolumn{4}{|l|}{ Psychosis } \\
\hline $\begin{array}{l}\text { Count } \\
\%\end{array}$ & $\begin{array}{c}5 \\
25.0 \%\end{array}$ & $\begin{array}{c}11 \\
39.3 \%\end{array}$ & $\begin{array}{c}5 \\
17.2 \%\end{array}$ \\
\hline \multicolumn{4}{|c|}{ (b) Current medication } \\
\hline $\begin{array}{l}\text { Count } \\
\%\end{array}$ & $10.0 \%$ & $\begin{array}{c}3 \\
10.7 \%\end{array}$ & $\begin{array}{c}4 \\
3.8 \%\end{array}$ \\
\hline \multicolumn{4}{|c|}{ Any antidepressant } \\
\hline $\begin{array}{l}\text { Count } \\
\%\end{array}$ & $\begin{array}{c}15 \\
75.0 \%\end{array}$ & $\begin{array}{c}14 \\
50.0 \%\end{array}$ & $\begin{array}{c}17 \\
58.6 \%\end{array}$ \\
\hline \multicolumn{4}{|c|}{ Any antipsychotic } \\
\hline $\begin{array}{l}\text { Count } \\
\%\end{array}$ & $\begin{array}{c}11 \\
55.0 \%\end{array}$ & $\begin{array}{c}18 \\
64 \%\end{array}$ & $\begin{array}{c}15 \\
51.7 \%\end{array}$ \\
\hline \multicolumn{4}{|c|}{ Any mood stabilizer } \\
\hline $\begin{array}{l}\text { Count } \\
\%\end{array}$ & $10.0 \%$ & $\begin{array}{c}7 \\
25.0 \%\end{array}$ & $\begin{array}{c}8 \\
27.6 \%\end{array}$ \\
\hline
\end{tabular}

$\chi^{2}$ for (i) cluster group by primary diagnosis $\left(\chi^{2}(4,77)=3.8, P=0.440\right)$; (ii) cluster group by 'any antidepressant' $\left(\chi^{2}(2,77)=3.2, P=0.201\right)$; (ii) cluster group by 'any antipsychotic' $\left(\chi^{2}(2,77)=1.0, P=0.616\right)$; (ii) cluster group by 'any mood stabiliser' $\left(\chi^{2}(2,77)=2.3, P=0.309\right)$. cluster group as compared with those of healthy controls. Twenty-five controls (aged 18-28 years) were selected consecutively with the goal of achieving a similar gender ratio (56\% females) as the patient group (54\% female). Omnibus ANOVA showed that the controls did not significantly differ from the three cluster groups in terms of age $(\mathrm{F}(3,101)=0.421, P=0.739)$, years of education $(\mathrm{F}(3,101)=2.491, P=0.065)$ or predicted IQ $(\mathrm{F}(3,93)=$ $0.511, P=0.676)$. Post hoc Dunnett's tests revealed only one significant difference $(P<0.05)$ between any of the cluster groups and controls; cluster 1 had fewer $(12.9 \pm 2.1)$ years of education compared with the controls $(14.6 \pm 1.8$ years).

The GM-corrected concentration scores for each metabolite/creatine across each cluster group were compared with controls (see Figure 4) and Dunnett's tests revealed the following: (i) cluster 1 had significantly $(P<0.001)$ higher levels of NAA/Cr and GLU/Cr; (ii) cluster 2 had significantly lower levels of $\mathrm{MI} / \mathrm{Cr}(P<0.05)$ but higher levels of $\mathrm{GSH} / \mathrm{Cr}$ $(P<0.01)$ and (ii) cluster 3 had significantly higher levels of $\mathrm{Ml} / \mathrm{Cr}$ compared with controls.

\section{Discussion}

This study proposes that three distinct subgroups of young patients presenting with admixtures of depressive and psychotic symptoms can be identified on the basis of ${ }^{1} \mathrm{H}$ MRS-derived ACC neurometabolite profiles. Notably, membership of these subgroups did not reflect other demographic or clinical features (for example, age, sex ratio, education,
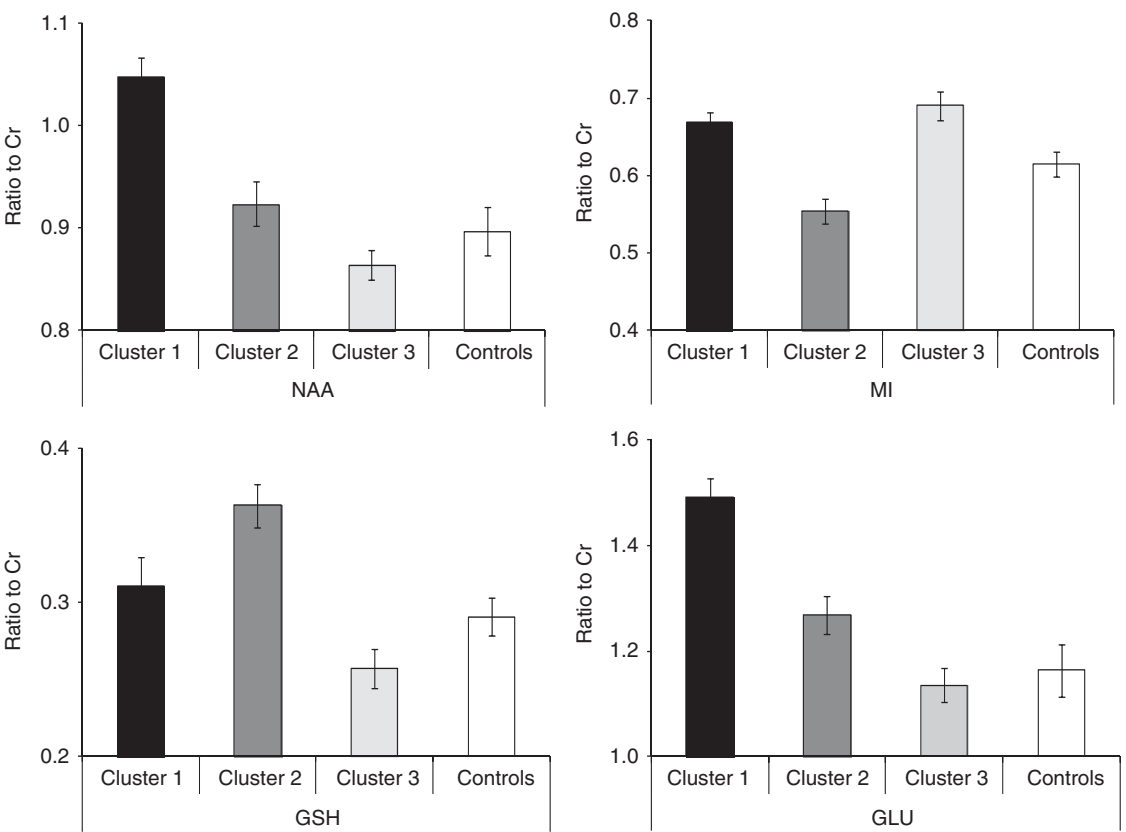

Figure 4 Gray-matter-corrected neurometabolite (clockwise from top left panel: NAA; MI; GLU; GSH) ratio to creatine (with standard error bars) for each cluster group versus controls. 
predicted IQ, current symptoms, psychological distress or distribution of primary diagnoses and current medication).

Three subgroup profiles were identified. Cluster 1, representing $26 \%$ of the cases, was characterized by increased levels of both NAA/Cr and GLU/Cr. This pattern of findings may represent a relationship between failed neuronal pruning (represented by increased NAA) and a consequent hyperfunctioning of (the glutamatergic) $\mathrm{N}$-methyl-D-aspartate receptor (NMDAr) system. ${ }^{33}$ Cluster 2 (36\% of the sample) was characterized by high levels of $\mathrm{GSH} / \mathrm{Cr}$ and low levels of $\mathrm{MI} / \mathrm{Cr}$. Elevated GSH signifies an increased capacity for the removal of reactive oxygen species most often due to increased accumulation of these free radicals. Taken together with decreased levels of $\mathrm{Ml}$, which is predominantly contained within the astrocyte, this may be reflective of mechanisms that underpin an oxidative stress reaction that may include the collateral elimination of glia. Cluster 3 (38\% of the sample) was characterized by low levels of NAA/Cr, GLU/Cr and GSH/ Cr suggestive of disruptions in GLU synthesis and neurotransmission. The observed reduction in GLU may also, in part, account for the reduced GSH, as GLU (along with cysteine and glycine) is a precursor of GSH synthesis. Aberrations in the bioavailability of GLU may ultimately result in a decrease in the brain's capacity to effectively neutralize reactive oxygen species via oxidative stress mechanisms.

Our findings suggest that there may be an association between NAA/Cr and GLU/Cr across the cluster groups, as evidenced by cluster 1 showing the highest levels of both metabolites, whereas cluster 3 showed the lowest levels of each. To our knowledge, few studies have demonstrated an association between in vivo NAA and GLU levels in psychiatric cohorts. A recent study ${ }^{34}$ has shown a strong correlation between absolute NAA and GLU concentrations in the hippocampus of older patients with stable bipolar disorder and although the GLU levels were significantly increased (compared with controls), their NAA levels were apparently normal. Numerous studies have shown that within the ACC, NAA is significantly decreased in patients with psychosis, ${ }^{17,35-37}$ bipolar disorder ${ }^{38,39}$ and depression. ${ }^{40-43}$ However, the stage of illness may assume an important role with evidence of increased ACC-NAA in adolescents with bipolar disorder $^{44}$ as well as in young adults with first-episode depression. ${ }^{42}$ There are also reports of no differences in ACC-NAA between ultra-high risk and first-episode psychosis individuals and healthy controls. ${ }^{45}$

Similarly, there are mixed findings with respect to ACCGLU across various patient groups at various stages of illness; this particular literature has been made even more complicated by the use of various ${ }^{1} \mathrm{H}$-MRS indices of in vivo GLU levels. A recent meta-analysis ${ }^{46}$ concluded that although ACC-GLU is reduced in major depression, it may be statedependent. Similarly, decreased ACC-GLU has been reported in schizophrenia. ${ }^{47,48}$ However, there are also null findings for psychosis, ${ }^{49}$ bipolar disorder ${ }^{50}$ and depression ${ }^{51}$ as well as separate evidence of increased ACC-GLU levels in bipolar disorder ${ }^{13,52}$ and psychosis. ${ }^{49} A$ recent review ${ }^{53}$ has suggested that GLU may distinguish depressive from manic episodes, with reduced levels consistent with the former and increased levels consistent with the latter. Our findings do not support this supposition, but there are subgroups of patients that differ in neurochemical profiles, and not necessarily their symptomatology or diagnosis.

Only one cluster group was distinguished by their levels of $\mathrm{Ml}$; although the remaining cluster groups showed normal levels, cluster 2 showed significantly decreased MI levels as compared with controls. Although decreased MI level has been shown within the ACC of those with major depression $^{43,54}$ and schizophrenia, ${ }^{48}$ there have been reports of null findings in bipolar disorder ${ }^{55}$ and depression ${ }^{56}$ as well as increased levels of ACC-MI in bipolar disorder. ${ }^{52}$

Interestingly, the least studied of these four metabolites, GSH, was strongly loaded onto the second DFA-determined function, which accounted for $40 \%$ of the variance between the clusters. Furthermore, as indicated in Figure 3, GSH appears to be the metabolite that most clearly distinguishes all three of the cluster groups. There are few studies that have assessed the GSH levels directly in relevant patient samples. Do et al. ${ }^{57}$ reported a significant decrease ( $\left.\sim 50 \%\right)$ of GSH within the prefrontal cortex of schizophreniform/schizophrenia patients. Matsuzawa et al. ${ }^{58}$ found no differences in GSH levels within the posterior medial frontal cortex of schizophrenic patients as compared with controls. By contrast, Wood et al. ${ }^{59}$ reported that GSH levels were increased in the medial temporal lobes of first-episode psychosis (FEP) patients. The latter authors attributed their reverse findings for GSH to the earlier clinical phase of their patients (that is compared with studies of older patients with chronic schizophrenia). This suggests that early in illness, at least for a subset of FEP patients, as there may be an oxidative stress reaction, a compensatory response is mounted (characterized by a surge in GSH).

Membership of these groups (according to this study) could now be used as the basis for stratifying future clinical trials of the efficacy of either novel (for example, omega-3 fatty acids, antioxidant therapies, glutamatergic agents) or other standard treatments (for example, antidepressants, Lithium, anticonvulsants, antipsychotics). Further, the importance of the GSH findings would point on the systematic evaluation of agents that may reduce oxidative stress early in the course of illness. Additionally, the change in metabolic profile in relation to each of the treatments provided has the potential to be used as a primary outcome measure. The extent to which the change in any measure (or profile of measures) is correlated with improved short- or long-term outcomes would need to be evaluated concurrently.

A major limitation of this study was the use of metabolite ratios to $\mathrm{Cr}$ rather than absolute concentration. This makes comparisons with some (particularly more recent) studies more difficult. In previous research, ratios to $\mathrm{Cr}$ have been employed as a means to reduce subject-specific variations in MRS data; recently, however, it has been suggested ${ }^{60}$ that this approach may be limited. Indeed some studies have found significant differences in absolute $\mathrm{Cr}$ levels for schizophrenia, $^{60}$ bipolar disorder ${ }^{13}$ and depression ${ }^{61}$ within the ACC/PFC as compared with healthy controls. On the other hand, there are studies that have provided evidence of no significant differences in absolute $\mathrm{Cr}$ concentration within the ACC of those with schizophrenia, ${ }^{35,47,49}$ bipolar disorder ${ }^{60,62}$ and depression. ${ }^{54,56}$ The issues relating to $\mathrm{Cr}$ ratios are vexed, however, by not determining absolute metabolite 
concentrations, we cannot rule out the potential confounds associated with ratio measurements. Equally, in this respect, it should be borne in mind that no significant difference in LCModel-determined $\mathrm{Cr}$ concentration was detected across all clusters.

Another limitation of this study was the potential influence of medication on spectroscopic findings. Although the distribution of medication exposure was relatively balanced across the cluster groups, the potential effects of psychotropic medications on each of these spectroscopic markers cannot be ruled out. Although some studies ${ }^{63,64}$ have found that antipsychotic exposure is associated with reduced NAA levels, there is conflicting evidence ${ }^{35}$ that these medications (as well as illness duration) have no direct effects on this neurometabolite. In support of this, Bustillo et al. ${ }^{65}$ found that there were no further changes in NAA or glutamine (GLN)/ GLU within the ACC following 12 months of antipsychotic treatment in a sample of young 'minimally-treated' schizophrenia patients. However, this study did not account for the potential effects of past substance use, and therefore the impact of this cannot be ruled out. Further, our attempt to compare the neurometabolite levels of each cluster group with those of healthy controls may have been compromised by subtle differences in age and years of education. Future studies would benefit by undertaking larger case-control and longitudinal designs to explicate the apparent abnormalities in the neurochemical markers revealed here.

Comparisons with some of the existing literature are difficult owing to the differences in acquisition parameters as well as hardware characteristics. This is particularly pertinent with respect to GSH, which under 'normal' experimental settings is difficult to resolve even at $3 \mathrm{~T}$. The quality of the data in such a setting is dependant on adequate signal to noise (SNR) ratio, and to this end the effective shimming of the scanner. Most reliably, GSH is resolved at $3 \mathrm{~T}$ using a MEGAPRESS acquisition sequence or quantum filtering techniques, however, with adequate SNR, it is also possible to resolve GSH using short TE-PRESS sequence with the appropriate use of a GSH basis set for analysis. In the case of our study, we were able to resolve $\mathrm{GSH}$ using an optimized $\mathrm{TE}=35$ PRESS sequence with all subjects included in the final analysis having CRLBs of less than $20 \%$. A similar argument also exists for resolving GLU from GLN. Although we did not investigate GLN in our study, we did reliably resolve GLU from GLN by negating the need to report a combined 'GLX' metabolite. Voxel size and placement can also differ substantially across studies, and in some cases, large 'prefrontal cortex' voxels can include the ACC (for example, see Taylor et $a .^{51}$ ). In addition, the relative content of gray matter, white matter and CSF within voxels across studies can also differ and as such can have an influence on the final metabolite concentration. Although in our study, we segmented the ACC voxel, and the results reported herein are those for gray matter only, comparisons with other studies that have not similarly corrected the acquisition voxel for gray matter content become more difficult.

If the field of translational psychiatry is ever likely to make real progress, then there is an urgent need to move away from poorly-validated diagnostic categories as the basis of evaluating potential markers of underlying pathophysiologies. This is particularly so when seeking to move clinical psychiatry from a late to an early-intervention focus (which is currently justified largely on the basis of reducing secondary psychosocial impairment rather than changing illness trajectories ${ }^{2}$ ). This study presents evidence that neurometabolic profiles, recorded by ${ }^{1} \mathrm{H}-\mathrm{MRS}$, may have a much greater capacity to differentiate young people than traditional clinical phenotypes, and that such differences in profiles may lead to more specific and targeted intervention studies.

\section{Conflict of interest}

The authors declare no conflict of interest.

Acknowledgements. This study was supported by the NHMRC Program Grant (No. 566529), Centres of Clinical Research Excellence Grant (No. 264611), NHMRC Australian Fellowship (No. 511921) and Clinical Research Fellowship (No. 402864). We would like to thank Manreena Kaur and Shantel Duffy for their assistance with data collection. We would also like to express our gratitude to individuals that participated in this study.

1. McGorry PD, Hickie IB, Yung AR, Pantelis C, Jackson HJ. Clinical staging of psychiatric disorders: a heuristic framework for choosing earlier, safer and more effective interventions. Aust N Z J Psychiatry 2006; 40: 616-622.

2. Hickie IB. Youth mental health: we know where we are and we can now say where we need to go next. Early Interv Psychiatry 2011; 5: 63-69.

3. Hamilton BA, Naismith SL, Scott EM, Purcell S, Hickie IB. Disability is already pronounced in young people with early stages of affective disorders: Data from an early intervention service. J Affect Disord 2011; 131: 84-91.

4. Hickie IB, Scott EM, Hermens DF, Naismith SL, Guastella AJ, Kaur M et al. Applying a clinical staging framework in young people who present with admixtures of anxious, depressive or psychotic symptoms. Early Interv Psychiatry 2012 (in press).

5. McGorry PD, Purcell R, Hickie IB, Yung AR, Pantelis C, Jackson HJ et al. Clinical staging: a heuristic model for psychiatry and youth mental health. Med J Aust 2007; 187: S40.

6. Insel TR. The arrival of preemptive psychiatry. Early Interv Psychiatry 2007; 1: 5-6.

7. McGorry PD. Risk syndromes, clinical staging and DSM V: new diagnostic infrastructure for early intervention in psychiatry. Schizophr Res 2010; 120: 49-53.

8. Hermens DF, Redoblado Hodge MA, Naismith SL, Kaur M, Scott E, Hickie IB. Neuropsychological clustering highlights cognitive differences in young people presenting with depressive symptoms. J Int Neuropsychol Soc 2011; 17: 267-276.

9. Yucel M, Lubman DI, Harrison BJ, Fornito A, Allen NB, Wellard RM et al. A combined spectroscopic and functional MRI investigation of the dorsal anterior cingulate region in opiate addiction. Mol Psychiatry 2007; 12: 691-702.

10. Barker PB. N-acetyl aspartate-a neuronal marker? Ann Neurol 2001; 49: 423-424

11. Griffin JL, Bollard M, Nicholson JK, Bhakoo K. Spectral profiles of cultured neuronal and glial cells derived from HRMAS 1H NMR spectroscopy. NMR Biomed 2002; 15: 375-384

12. Verkhratsky A, Kirchhoff F. NMDA receptors in glia. The Neuroscientist 2007; 13: 28-37.

13. Frye MA, Watzl J, Banakar S, O'Neill J, Mintz J, Davanzo P et al. Increased anterior cingulate/medial prefrontal cortical glutamate and creatine in bipolar depression. Neuropsychopharmacology 2007; 32: 2490-2499.

14. Mayberg HS, Brannan SK, Mahurin RK, Jerabek PA, Brickman JS, Tekell JL et al Cingulate function in depression: a potential predictor of treatment response. Neuroreport 1997; 8: 1057-1061.

15. Drevets WC. Prefrontal cortical-amygdalar metabolism in major depression. Ann N Y Acad Sci 1999; 877: 614-637.

16. Wood SJ, Yucel M, Velakoulis D, Phillips LJ, Yung AR, Brewer W et al. Hippocampal and anterior cingulate morphology in subjects at ultra-high-risk for psychosis: the role of family history of psychotic illness. Schizophr Res 2005; 75: 295-301.

17. Wood SJ, Yucel M, Wellard RM, Harrison BJ, Clarke K, Fornito A et al. Evidence for neuronal dysfunction in the anterior cingulate of patients with schizophrenia: a proton magnetic resonance spectroscopy study at 3T. Schizophr Res 2007; 94: 328-331.

18. Brown JW, Braver TS. A computational model of risk, conflict, and individual difference effects in the anterior cingulate cortex. Brain Res 2008; 1202: 99-108.

19. Borgen FH, Barnett DC. Applying cluster analysis in counseling psychology research. $J$ Counseling Psychol 1987; 34: 456-458.

20. Delano-Wood L, Bondi MW, Sacco J, Abeles N, Jak AJ, Libon DJ et al. Heterogeneity in mild cognitive impairment: differences in neuropsychological profile and associated white matter lesion pathology. J Int Neuropsychol Soc 2009; 15: 906-914. 
21. Baumgartner R, Somorjai R, Summers R, Richter W, Ryner L, Jarmasz $M$ et al. Resampling as a cluster validation technique in fMRI. J Magn Reson Imaging 2000; 11: 228-231.

22. Scott E, Naismith SL, Whitwell BG, Hamilton B, Chudleigh C, Hickie IB et al. Delivering youth-specific mental health services: the advantages of a collaborative, multi-disciplinary system. Australas Psychiatry 2009; 17: 189-194.

23. American Psychiatric Association. Diagnostic and Statistical Manual of Mental Disorders, 4th edn TR. American Psychiatric Association: Washington DC, 2000

24. Hamilton M. Development of a rating scale for primary depressive illness. Br J Soc Clin Psychol 1967; 6: 278-296.

25. Overall JE, Gorham DR. The brief psychiatric rating scale. Psychol Reports 1962; 10: 799-812.

26. Goldman HH, Skodol AE, Lave TR. Revising axis V for DSM-IV: a review of measures of social functioning. Am J Psychiatry 1992; 149: 1148-1156.

27. Kessler RC, Andrews G, Colpe LJ, Hiripi E, Mroczek DK, Normand SL et al. Short screening scales to monitor population prevalences and trends in non-specific psychological distress. Psychol Med 2002; 32: 959-976.

28. Andrews G, Slade T. Interpreting scores on the Kessler psychological distress scale (K10). Aust N Z J Public Health 2001; 25: 494-497.

29. Talairach J, Tournoux P. Co-planar stereotaxic atlas of the human brain: 3-dimensional proportional system: an approach to cerebral imaging. Thieme: New York, 1987.

30. Provencher SW. Estimation of metabolite concentrations from localized in vivo proton NMR spectra. Magn Reson Med 1993; 30: 672-679.

31. Zhang Y, Brady M, Smith S. Segmentation of brain MR images through a hidden Markov random field model and the expectation-maximization algorithm. IEEE Trans Med Imaging 2001; 20: 45-57.

32. Norusis MJ. PASW Statistics 18 Guide to Data Analysis. Prentice Hall, 2010.

33. Stoneham ET, Sanders EM, Sanyal M, Dumas TC. Rules of engagement: factors that regulate activity-dependent synaptic plasticity during neural network development. Biol Bull 2010; 219: 81-99.

34. Colla M, Schubert F, Bubner M, Heidenreich JO, Bajbouj M, Seifert F et al. Glutamate as a spectroscopic marker of hippocampal structural plasticity is elevated in long-term euthymic bipolar patients on chronic lithium therapy and correlates inversely with diurnal cortisol. Mol Psychiatry 2008; 14: 696-704.

35. Deicken RF, Zhou L, Schuff N, Weiner MW. Proton magnetic resonance spectroscopy of the anterior cingulate region in schizophrenia. Schizophr Res 1997; 27: 65-71.

36. Reid MA, Stoeckel LE, White DM, Avsar KB, Bolding MS, Akella NS et al. Assessments of function and biochemistry of the anterior cingulate cortex in schizophrenia. Biol Psychiatry 2010; 68: 625-633

37. Premkumar P, Parbhakar VA, Fannon D, Lythgoe D, Williams SC, Kuipers E et al. N-acetyl aspartate concentration in the anterior cingulate cortex in patients with schizophrenia: a study of clinical and neuropsychological correlates and preliminary exploration of cognitive behaviour therapy effects. Psychiatry Res: Neuroimaging 2010; 182: 251-260.

38. Caetano SC, Olvera RL, Hatch JP, Sanches M, Chen HH, Nicoletti M et al. Lower N-acetylaspartate levels in prefrontal cortices in pediatric bipolar disorder: a $1 \mathrm{H}$ magnetic resonance spectroscopy study. J Am Acad Child Adolesc Psychiatry 2011; 50: 85-94.

39. Yildiz-Yesiloglu A, Ankerst DP. Neurochemical alterations of the brain in bipolar disorder and their implications for pathophysiology: a systematic review of the in vivo proton magnetic resonance spectroscopy findings. Prog Neuro-Psychopharmacol Biol Psychiatry 2006; 30: 969-995

40. Merkl A, Schubert F, Quante A, Luborzewski A, Brakemeier E-L, Grimm S et al. Abnormal cingulate and prefrontal cortical neurochemistry in major depression after electroconvulsive therapy. Biol Psychiatry 2011; 69: 772-779.

41. Olvera RL, Caetano SC, Stanley JA, Chen H-H, Nicoletti M, Hatch JP et al. Reduced medial prefrontal N-Acetyl-Aspartate levels in pediatric major depressive disorder: A multivoxel in vivo1H spectroscopy study. Psychiatry Res: Neuroimaging 2010; 184: 71-76.

42. Portella MJ, de Diego-Adelino J, Gomez-Anson B, Morgan-Ferrando R, Vives Y, Puigdemont $D$ et al. Ventromedial prefrontal spectroscopic abnormalities over the course of depression: a comparison among first episode, remitted recurrent and chronic patients. J Psychiatr Res 2011; 45: 427-434.

43. Järnum $H$, Eskildsen SF, Steffensen EG, Lundbye-Christensen S, Simonsen $C W$, Thomsen IS et al. Longitudinal MRI study of cortical thickness, perfusion, and metabolite levels in major depressive disorder. Acta Psychiatr Scand 2011; 124: 435-446.

44. Patel NC, Cecil KM, Strakowski SM, Adler CM, DelBello MP. Neurochemical alterations in adolescent bipolar depression: A proton magnetic resonance spectroscopy pilot study of the prefrontal cortex. J Child Adolesc Psychopharmacol 2008; 18: 623-627.

45. Uhl I, Mavrogiorgou P, Norra C, Forstreuter F, Scheel M, Witthaus $\mathrm{H}$ et al. 1H-MR spectroscopy in ultra-high risk and first episode stages of schizophrenia. J Psychiatr Res 2011; 45: 1135-1139.
46. Luykx JJ, Laban KG, van den Heuvel MP, Boks MPM, Mandl RCW, Kahn RS et al. Region and state specific glutamate downregulation in major depressive disorder: a meta-analysis of 1H-MRS findings. Neurosci Biobehav Rev 2012; 36: 198-205.

47. Theberge J, Al-Semaan Y, Williamson PC, Menon RS, Neufeld RWJ, Rajakumar N et al. Glutamate and glutamine in the anterior cingulate and thalamus of medicated patients with chronic schizophrenia and healthy comparison subjects measured with 4.0-T proton MRS Am J Psychiatry 2003; 160: 2231-2233.

48. Tayoshi SY, Sumitani S, Taniguchi K, Shibuya-Tayoshi S, Numata S, Iga J-I et al. Metabolite changes and gender differences in schizophrenia using 3-Tesla proton magnetic resonance spectroscopy (1H-MRS). Schizophr Res 2009; 108: 69-77.

49. Theberge J, Bartha R, Drost DJ, Menon RS, Malla A, Takhar J et al. Glutamate and glutamine measured with $4.0 \mathrm{~T}$ proton MRS in never-treated patients with schizophrenia and healthy volunteers. Am J Psychiatry 2002; 159: 1944-1946.

50. Moore CM, Frazier JA, Glod CA, Breeze JL, Dieterich M, Finn CT et al. Glutamine and glutamate levels in children and adolescents with bipolar disorder: A 4.0-T proton magnetic resonance spectroscopy study of the anterior cingulate cortex. J Am Acad Child Adolesc Psychiatry 2007; 46: 524-534.

51. Taylor MJ, Selvaraj S, Norbury R, Jezzard P, Cowen PJ. Normal glutamate but elevated myo-inositol in anterior cingulate cortex in recovered depressed patients. J Affect Disord 2009; 119: 186-189.

52. Öngür D, Jensen JE, Prescot AP, Stork C, Lundy M, Cohen BM et al. Abnormal glutamatergic neurotransmission and neuronal-glial interactions in acute mania. Biol Psychiatry 2008; 64: 718-726.

53. Yuksel C, Ongur D. Magnetic resonance spectroscopy studies of glutamate-related abnormalities in mood disorders. Biol Psychiatry 2010; 68: 785-794.

54. Coupland NJ, Ogilvie CJ, Hegadoren KM, Seres P, Hanstock CC, Allen PS. Decreased prefrontal myo-inositol in major depressive disorder. Biol Psychiatry 2005; 57: 1526-1534.

55. Moore CM, Breeze JL, Gruber SA, Babb SM, DeB Frederick B, Villafuerte RA et al. Choline, myo-inositol and mood in bipolar disorder: a proton magnetic resonance spectroscopic imaging study of the anterior cingulate cortex. Bipolar Disord 2000; 2. 207-216.

56. Auer DP, Pütz B, Kraft E, Lipinski B, Schill J, Holsboer F. Reduced glutamate in the anterior cingulate cortex in depression: an in vivo proton magnetic resonance spectroscopy study. Biol Psychiatry 2000; 47: 305-313.

57. Do KQ, Trabesinger AH, Kirsten-Kruger M, Lauer CJ, Dydak U, Hell D et al. Schizophrenia: glutathione deficit in cerebrospinal fluid and prefrontal cortex in vivo. Eur J Neurosci 2000; 12: $3721-3728$

58. Matsuzawa D, Obata $T$, Shirayama $Y$, Nonaka $H$, Kanazawa $Y$, Yoshitome $E$ et al. Negative correlation between brain glutathione level and negative symptoms in schizophrenia: A 3 T 1H-MRS study. PLOS ONE 2008; 3: e1944.

59. Wood SJ, Berger GE, Wellard RM, Proffitt T-M, McConchie M, Berk M et al. Medial temporal lobe glutathione concentration in first episode psychosis: A 1H-MRS investigation. Neurobiol Dis 2009; 33: 354-357.

60. Ongur D, Prescot AP, Jensen JE, Cohen BM, Renshaw PF. Creatine abnormalities in schizophrenia and bipolar disorder. Psychiatry Res Neuroimaging 2009; 172: 44-48.

61. Gruber S, Frey R, Mlynarik V, Stadlbauer A, Heiden A, Kasper S et al. Quantification of metabolic differences in the frontal brain of depressive patients and controls obtained by 1H-MRS at 3 Tesla. Invest Rad 2003; 38: 403-408.

62. Dager SR, Friedman SD, Parow A, Demopulos C, Stoll AL, Lyoo IK et al. Brain metabolic alterations in medication-free patients with bipolar disorder. Arch Gen Psychiatry 2004; 61: 450-458.

63. Ende G, Braus DF, Walter S, Weber-Fahr W, Soher B, Maudsley AA et al. Effects of age, medication, and illness duration on the $\mathrm{N}$-acetyl aspartate signal of the anterior cingulate region in schizophrenia. Schizophr Res 2000; 41: 389-395.

64. Brugger S, Davis JM, Leucht S, Stone JM. Proton magnetic resonance spectroscopy and illness stage in schizophrenia-A systematic review and meta-analysis. Biol Psychiatry 2011; 69: 495-503.

65. Bustillo JR, Rowland LM, Mullins P, Jung R, Chen $\mathrm{H}$, Qualls $\mathrm{C}$ et al. $1 \mathrm{H}-\mathrm{MRS}$ at 4 Tesla in minimally treated early schizophrenia. Mol Psychiatry 2010; 15: 629-636.

Translational Psychiatry is an open-access journal published by Nature Publishing Group. This work is licensed under the Creative Commons Attribution-Noncommercial-No Derivative Works 3.0 Unported License. To view a copy of this license, visit http://creativecommons.org/licenses/by-nc-nd/3.0/ 